in vivo $34: 1811-1821(2020)$

doi:10.21873/invivo.11976

\title{
Biofunctional Feed Supplemented With By-products of Olive Oil Production Improves Tissue Antioxidant Profile of Lambs
}

\author{
SOTIRIA MAKRI ${ }^{1}$, SOFIA RAFTOPOULOU ${ }^{1}$, IOANNIS KAFANTARIS ${ }^{1}$, \\ BASILIKI KOTSAMPASI ${ }^{2}$, VLADIMIROS CHRISTODOULOU ${ }^{2}$, \\ CHARITINI NEPKA ${ }^{3}$, ARISTIDIS S. VESKOUKIS ${ }^{1}$ and DEMETRIOS KOURETAS ${ }^{1}$ \\ ${ }^{1}$ Department of Biochemistry and Biotechnology, University of Thessaly, Larissa, Greece; \\ ${ }^{2}$ Research Institute of Animal Science/Hellenic Agricultural Organization Demeter, Giannitsa, Greece; \\ ${ }^{3}$ Department of Pathology, University Hospital of Larissa, Larissa, Greece
}

\begin{abstract}
Background/Aim: Olive mill wastewater (OMW) is a byproduct of olive oil production. The aim of the study was to estimate the redox profile of lambs' vital organs after consumption of an OMW-supplemented feed. Materials and Methods: Twenty-four lambs received breast milk until day 15. Then, they were divided in two groups: control and OMW, $n=12$ each. The control group received standard ration, while the OMW group received OMW enriched feed along with mother's milk until day 42 and animals ( $n=6$ per group) were sacrificed. The remaining 12 received the feeds until day 70 and sacrificed. Tissue samples were collected at day 42 and 70 and specific redox biomarkers were assessed. Results: Overall, the OMW feed improved tissue redox profile by affecting the glutathione $S$-transferase (GST) activity and $\gamma$-glutamate-cysteine ligase $(\gamma-G C L)$ expression in all tested tissues. Superoxide dismutase (SOD) activity was not affected. Conclusion: The polyphenol-rich byproduct reinforced lamb redox profile and may putatively improve their wellness and productivity.
\end{abstract}

Olive oil is an extract derived from olives and it has been mostly used in the Mediterranean basin since the $8^{\text {th }}$ millennium BC (1). Olive oil production rates vary between countries, such as Spain, Italy, Tunisia and Portugal, which

This article is freely accessible online.

Correspondence to: Demetrios Kouretas, Professor, University of Thessaly, Department of Biochemistry and Biotechnology, Viopolis, Mezourlo, Larissa 41500, Greece. Tel: +30 2410565277, Fax: +30 2410565293,e-mail: dkouret@uth.gr

Key Words: Olive oil mill wastewater, glutathione S-transferase, superoxide dismutase, $\gamma$-glutamate-cysteine ligase, environment. according to the Food and Agriculture Organization of the United Nations are among the leading producers of olive oil worldwide (FAOSTAT). According to the same source, Greece is responsible for an average annual production of 344,615 tons of olive oil from 1993 to 2014 being, thus, third in the ranking of olive oil producer countries. On the basis of the Integrated Pollution Prevention and Control (IPPC) Directive, European industries produce $72 \%$ of the olive oil produced annually worldwide (Spain: $45 \%$, Italy: 15\%, Greece: $10 \%$ ) (2). The extraction and production of olive oil in Greece is carried out in approximately 2,800 small-scale agro-industrial units scattered throughout the country $(3,4)$.

Although olive oil production is a fundamental procedure for the economy of every country, it is known that it can promote environmental pollution due to the generation of two waste streams, namely olive mill residual solids and olive mill wastewater (OMW) (3). OMW is mainly characterized not only by high organic content and complex organic substances but also by the presence of diverse phenolic compounds (5). These compounds are monocyclic and polymeric aromatic molecules and are responsible for the dark color, the phytotoxicity, the antibacterial properties and the unpleasant odor of $\operatorname{OMW}(3,5,6)$. OMW has an acidic $\mathrm{pH}$, ranging between 4 and 5 , and mostly consists of polyphenols and tannins, while the $2-15 \%$ of its organic fraction is also rich in phenolic compounds with a concentration range between 3 and $10 \mathrm{~g} / 1$ (3, 5).

Olive mill residues are reach in polyphenolic compounds, such as caffeic acid, coumaric acid, ferulic acid, gallic acid, hydroxybenzoic acid, kaempherol and quercetin. However, oleuropein, tyrosol and hydroxytyrosol are the most crucial compounds found in OMW that possess potent antioxidant activity $(3,7-10)$. Studies have shown that polyphenolic compounds $(11,12)$ and especially compounds present in OMW partly protected animals and humans from oxidative 
stress related diseases, such as neurodegenerative pathologies, several cancer types, diabetes, rheumatoid arthritis and other chronic conditions (7, 13-19). It has been reported that farm animals during the early stages of their lives have impaired antioxidant mechanisms compared to their adult counterparts, due to several stress factors (e.g., heat stress, weaning, dietary imbalances and respiratory diseases). According to the World Organization of Animal Health, animal welfare is "the physical and mental state of an animal in relation to the conditions in which it lives and dies" (20), so the aforementioned conditions and other common oxidative stress related diseases (i.e., mastitis, enteritis, pneumonia) negatively affect their productivity and welfare $(21,22)$. Therefore, it becomes evident that supplementation of their diet with specific antioxidants could possibly act protectively $(7,23-26)$. Nowadays, there is an increasing interest regarding the beneficial health implications of bioactive compounds and especially polyphenols. They are present in natural products (i.e., fruits, cereals, vegetables), have the ability to scavenge free radicals, and when consumed by animals contribute to their protection against chronic diseases and the improvement of their welfare $(3,27-29)$. Polyphenols present in olive oil and especially in its byproducts are capable of protecting human erythrocytes from oxidative damage, since they scavenge reactive oxygen species (ROS) (30). Recent studies of our group have already demonstrated that feed supplemented with byproducts from the agricultural and the agro-industrial sector, such as grape pomace, olive oil mill wastes and sheep/goat whey protein, increase the antioxidant capacity of blood and of vital organs from livestock and laboratory animals, acting protectively in general (3, 7, 31-35).

Except for their potentially beneficial effects analyzed above, OMW is a serious environmental pollutant. It is known that there are plenty of new technologies that have been recently developed in order to reduce the pollution burden of OMW. Traditionally, OMW is usually discarded into nearby rivers and streams significantly polluting the waters that receive it. Specifically, the uncontrolled discharge of OMW into natural waters decreases the amount of dissolved oxygen and, therefore, harms the species of fauna and flora dwelling in these ecosystems $(36,37)$. Additionally, the increasing algal content induced by phosphorus compounds present in OMW causes eutrophication, thus destroying the ecological balance and quality of natural waters (6). Physicochemical technologies, such as dilution, evaporation, filtration, sedimentation and centrifugation, as well as biological (both aerobic and anaerobic) methodologies have already been investigated, but these methods are characterized by high cost, whereas they require specialized personnel for their operation $(6,38)$. Hence, it is necessary to invent cost-effective and environmentally friendly methods for handling the wastes produced during olive oil generation process and to adopt alternative methods for the exploitation of these byproducts enhancing the model of circular economy $(4,39,40)$.

Based on the above, OMW exerts dual biological action. It is a pollutant when discarded to the environment due to its high organic load, but, on the other hand, its high content in polyphenolic compounds contributes to the improvement of blood and tissue redox status and can potentially act protectively against oxidative stress related pathologies. Thus, the aim of the present study was to assess the putative beneficial role of a biofunctional feed generated via the incorporation of OMW in the conventional feed of productive animals on the activity and expression of antioxidant enzymes in vital organs (i.e., brain, heart and quadriceps muscle) of lambs. Our findings are anticipated to provide evidence regarding the effects of OMW in fundamental tissue antioxidant mechanisms. As a result, animals fed with OMW-supplemented feed could have improved welfare and productivity as well as reduced risk of disease outbreak. Additionally, taking into consideration the fact that oxidative stress impairs the quality of meat products, meat from lambs fed with OMW may have a better taste and organoleptic characteristics in general and enhanced biological properties. Moreover, the large-scale harnessing of this oil industry byproduct as a component of biofunctional feed will undisputedly reduce the burden of environmental pollution caused by its uncontrolled disposal, since, it can putatively reduce the eutrophication of neighboring aquatic ecosystem.

\section{Materials and Methods}

Olive mill wastewater $(O M W)$. OMW, which is a byproduct of olive oil production, was obtained from a local olive oil mill in Larissa, (Greece) without any further processing, in October 2014 (3). The chemical composition of OMW has already been published from our research group (9). Indicatively, it was found to be rich in four polyphenols, namely hydroxytyrosol, tyrosol, caffeic acid, and pcoumaric acid, which are main constituents of olive oil $(41,42)$.

Feed and silage preparation. OMW was added in the conventional lamb feed as a corn silage with specific ratio between solid and liquid compounds, according to the process previously published by our group $(3,7,32)$. Control silage contained $60 \%$ corn and $40 \%$ water as solid and liquid constituents, respectively, whereas experimental/biofunctional silage (i.e., feed supplemented with OMW) contained $52.5 \%$ corn and $7.5 \%$ OMW (equal to $60 \%$ solid material) and $40 \%$ water. The control and experimental silage were incorporated in the final administered feed (3).

Animals and experimental design. The Research Institute of Animal Science (Paralimni, Giannitsa, Greece/Hellenic Agricultural Organization - Demeter) was the host institute of the lambs. The conditions of the animal development and the experimental procedure were in accordance with the EU Directive 2010/63/EU for animal experiments. The experimental protocol was reviewed 
Makri et al: Olive Oil Industry By-products Improve Redox Profile of Lambs

Table I. Ingredients and nutrient composition (\% w/w) of both the control and the experimental diets before and after weaning, as previously reported (2).

\begin{tabular}{lccccc}
\hline & \multicolumn{2}{c}{ Before weaning } & & \multicolumn{2}{c}{ After weaning } \\
\cline { 2 - 3 } \cline { 6 - 6 } Ingredients & Control & OMW & & Control & OMW \\
\hline Corn silage $^{\mathrm{a}}$ & 45.0 & 45.0 & & 45.0 & 45.0 \\
Wheat bran & 9.0 & 9.0 & & 15.0 & 15.0 \\
Wheat meal & - & - & & 13.0 & 13.0 \\
Soybean meal 44\% CP & 21.0 & 21.0 & & 18.0 & 18.0 \\
Milk replacer & 20.0 & 20.0 & & - & - \\
Vitamin and mineral & 2.5 & 2.5 & & 2.5 & 2.5 \\
premix (2.5\%) & & & & \\
Sunflower meal & - & - & & 4.0 & 4.0 \\
Salt & 0.5 & 0.5 & & 0.5 & 0.5 \\
Limestone & 1.2 & 1.2 & & 1.2 & 1.2 \\
Monocalcium phosphate & 0.8 & 0.8 & & 0.8 & 0.8 \\
\hline
\end{tabular}

asilage contained $60 \%$ corn and $40 \%$ water as solid and liquid constituents, respectively, whereas OMW contained 52.5\% corn and 7.5\% OMW (equal to $60 \%$ solid material) and $40 \%$ water. OMW: Olive mill wastewater; $\mathrm{CP}$ : crude protein.

and approved by the Institutional Review Board of the University of Thessaly (no. 89/10.12.2014). With respect to the experimental design, 24 newborn male lambs of Chios breed were randomly selected from the flock hosted at the institute. For the first 15 days of their life they were breast feeding. Subsequently, they were equally and randomly divided into two homogeneous groups (i.e., 12 lambs per group) as follows: (a) control group consisted of lambs fed with both mother's milk and standard feed and (b) OMW group comprising lambs fed with both mother's milk and the biofunctional feed containing silage with OMW for the next 27 days (i.e., from day 15 to day 42). On day 42, 6 out of 12 animals of each group were sacrificed and the tissues of interest were harvested. After weaning (i.e., day 42), the rest of the animals of the control and the experimental groups were fed only with standard feed or OMW, respectively, for 28 more days (from day 42 to day 70). The exact composition of the feed of the two groups before and after weaning is indicated in Table I. Finally, the remaining 6 animals from each group were also sacrificed on day 70 and the same tissues, as on day 42 , were also collected. The experimental design of the present study is illustrated in Figure 1. Until the day of weaning, the lambs of each group remained along with the ewes in two separate stalls (one for each group) and had access to feed, alfalfa hay and water ad libitum. The ewes were fed with standard feed without having access to the feed supplemented with OMW and were separated from the lambs on day 42 . Then, lambs were completely separated from the ewes, till the end of the experiment (i.e., day 70). For sample collection, two experimental time points were selected (i.e., day 42 and day 70). At the first time point, the lambs were at a relatively young age when their antioxidant defense mechanisms are considered weak, and it is crucial to examine how feed supplemented with OMW affects these mechanisms and/or protects them from oxidative damage. The second time point was selected because the lambs are close to the age of slaughter for meat consumption and commercial exploitation. It is important to determine their redox status at this mature age, since, as mentioned above, oxidative stress significantly alters meat quality and its organoleptic properties (53-56).

Tissue collection and homogenization. The heart, brain and quadriceps muscle were collected on days 42 and 70 from the 24 lambs of both control and experimental groups ( $n=6$ lambs for each time point and group). All procedures (e.g., slaughter, bleeding, gutting, viscera separation and washing) were carried out by specialized staff according to industry-accepted guidelines. In order to minimize suffering, lambs were transferred to the slaughterhouse and stunned prior to slaughtering. After dissection, the collected tissues were cut into small pieces, placed into tubes and snapped frozen in liquid nitrogen. In preparation for biochemical analysis, the homogenization was carried out as described previously (7). Briefly, $100 \mathrm{mg}$ of each tissue was mixed with $1 \mathrm{ml}$ of phosphate buffered saline [PBS (0.01 M, pH=7.4, Gibco, ThermoFisher Scientific, Waltham, MA, USA)] containing a cocktail of protease inhibitor tablet (Complete ${ }^{\mathrm{TM}}$ mini protease inhibitors, Roche). The tissue samples were ground using a special portable homogenizer, the mixture was vigorously vortexed and briefly sonicated $(0.7$ cycle, $70 \%$ amplitude) on ice. Then, the homogenate was centrifuged $\left(10,000 \times \mathrm{g}, 15 \mathrm{~min}, 4^{\circ} \mathrm{C}\right)$, the supernatant (i.e., the tissue homogenate) was collected and total protein concentration was measured using the Bradford assay (Sigma Aldrich, Munich, Germany). All tissues were stored at $-80^{\circ} \mathrm{C}$ until further analysis.

Determination of glutathione S-transferase (GST) activity. GST activity in the tissue homogenate was measured according to the method of Habig et al. (1974) (43) as described previously (7, 11, $44)$. Briefly, the appropriate amount of potassium phosphate buffer $\left(\mathrm{K}_{2} \mathrm{HPO}_{4}\right.$ and $\left.\mathrm{KH}_{2} \mathrm{PO}_{4}, 100 \mathrm{mM}, \mathrm{pH}=7.4\right)$ was mixed with $50 \mu \mathrm{l}$ of $1 \mathrm{mM}$ GSH solution and $20 \mu \mathrm{l}$ of $1 \mathrm{mM}$ 1-chloro-2,4-dinitrobenzene (CDNB, Sigma-Aldrich) diluted in 95\% ethanol and the samples were incubated at $37^{\circ} \mathrm{C}$ for $5 \mathrm{~min}$. This was followed by the addition of $30 \mu \mathrm{l}$ of heart, $20 \mu \mathrm{l}$ of brain and $50 \mu \mathrm{l}$ of quadriceps homogenates (the protocol requires $>10 \mu \mathrm{g}$ of total protein in the tested sample) and the change in absorbance was monitored at 340 $\mathrm{nm}$ for 5 min using a spectrophotometer (HITACHI, U-1900 UV/VIS, Hitachi High Technologies America, Inc., Dallas, Texas, USA). Samples containing phosphate buffer instead of tissue homogenate were used as blanks and their absorbance was also monitored. GST activity was normalized to the total protein concentration of each sample and was assessed based on the molar extinction coefficient of CDNB $(9600 \mathrm{l} / \mathrm{mol} / \mathrm{cm})$.

Determination of superoxide dismutase (SOD) activity. The determination of SOD activity was based on the method of Oberley and Spitz (1984) (45) and performed as previously described (7, 11, 44). Specifically, the assay included a negative control made by mixing $800 \mu \mathrm{l}$ of SOD buffer [comprising $1 \mathrm{mM}$ diethylenetriaminepentaacetic acid (DETAPAC, Sigma-Aldrich) in $50 \mathrm{mM}$ potassium phosphate buffer $(\mathrm{pH}=7.8), 56 \mu \mathrm{M}$ nitroblue tetrazolium salt (NBT, Sigma-Aldrich) and $0.1 \mathrm{mM}$ xanthine (Sigma-Aldrich)] with $200 \mu \mathrm{l}$ of DETAPAC. Subsequently, $100 \mu \mathrm{l}$ of $60 \mathrm{mU}$ xanthine oxidase (XO, Sigma-Aldrich) were added and the rate of increase in absorbance was monitored at $560 \mathrm{~nm}$ for 3 min. In the test samples, $100 \mu \mathrm{l}$ of each tissue sample (the protocol requires $>10 \mu \mathrm{g}$ of total protein) were added to $800 \mu \mathrm{l}$ of SOD buffer followed by the addition of $100 \mu \mathrm{l}$ of $60 \mathrm{mU} \mathrm{XO}$ and the rate 


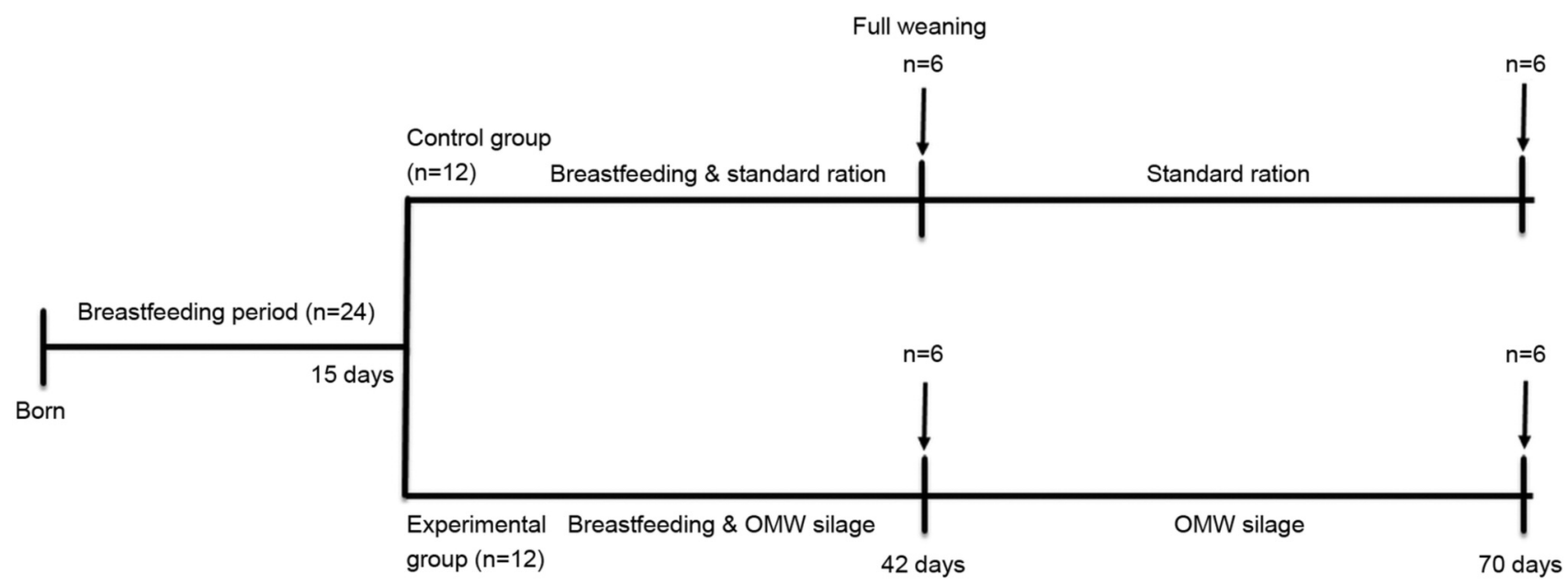

Figure 1. The experimental design.

of increase in absorbance was monitored at $560 \mathrm{~nm}$ for $3 \mathrm{~min}$. SOD activity was normalized to the total protein concentration of each sample and its calculation was based on the percent inhibition of the rate of absorbance increase according to the following equation:

$\%$ Inhibition $=\left[\left(\Delta \mathrm{A}_{560 \mathrm{~nm} / \mathrm{min} \text { negative control }}-\Delta \mathrm{A}_{560 \mathrm{~nm} / \mathrm{min} \text { sample }}\right) /\right.$

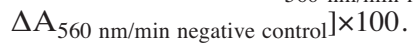

Western blot analysis of $\gamma$-glutamate-cysteine ligase $(\gamma-G C L)$ protein expression. In order to determine the expression levels of $\gamma$ GCL via immunoblotting, $30 \mu \mathrm{g}$ of protein from each tissue homogenate were used. The samples were separated by an $8 \%$ sodium dodecyl sulfate-polyacrylamide gel electrophoresis (SDSPAGE). Then, proteins were transferred onto polyvinylidene difluoride membranes (PVDF) (Millipore, Bedford, MA, USA). The membranes were blocked overnight with 5\% non-fat milk in buffer [13 mM Tris (Serva, Heidelberg, Germany), $150 \mathrm{mM}$ sodium chloride (Sigma-Aldrich), $\mathrm{pH}=7.5$ ] containing $0.2 \%$ Tween-20 (Sigma-Aldrich). Then, they were probed with polyclonal rabbit anti-human/mouse $\gamma$-GCL (1:625, Sigma-Aldrich; Cat. No AV54576) primary antibodies for $1 \mathrm{~h}$ at room temperature (RT). The membranes were then incubated with polyclonal horseradish peroxidase conjugated goat anti-rabbit secondary antibody (1:5000, Thermo Scientific, Cat. No 31462) for $30 \mathrm{~min}$ at RT. Then, they were re-probed with monoclonal anti-turkey/monkey/canine/ chicken/human/bovine/rat/mouse/mink/rabbit/hamster glyceraldehyde 3-phosphate dehydrogenase (GAPDH), (1:10000, Sigma-Aldrich, Cat. No G9295) as internal control. The optical density of the protein bands was measured via the Alpha View quantification software (Alpha Innotech, San Leandro, CA, USA).

Statistical analysis. Data were analyzed by one-way ANOVA followed by Tukey's post hoc test for comparing the means between the different groups. The differences between the two different groups of standard and OMW feed were analyzed at the same time point and not at the different time points (i.e. 42 and 70 day). Differences were considered significant at $p<0.05$. All results are expressed as mean \pm standard error of the mean (SEM). The statistical analyses were performed using SPSS software, version 20.0 (SPSS Inc., Chicago, IL, USA).

\section{Results}

GST activity was significantly decreased in the heart by $51 \%$ on day 42 in the OMW group compared to the control (Figure 2A), while no effect was observed in other tested tissues (Figure 2B, C). Regarding the second time point (i.e. 70 days), GST activity was significantly increased in the heart and quadriceps muscle by $58.6 \%$ and $150 \%$ (Figure $2 \mathrm{~A}, \mathrm{C}$ ) in the OMW group compared to the control group, respectively. No effect was observed in brain (Figure 2B).

Regarding SOD activity, no significant differences were observed in any tissue or time point (Figure 3A, B, C).

Expression of $\gamma$-GCL protein was significantly increased in the brain by $137.2 \%$ (Figure 4B) in the OMW group in comparison to the control group, on day 42 , whereas no effect was observed in the heart (Figure 4A) and quadriceps muscle (Figure 4C). However, on day $70, \gamma$-GCL protein levels were significantly increased in the heart, brain and quadriceps muscle by $430.8 \%, 52.4 \%$ and $313.3 \%$, respectively, in the OMW group compared to the control (Figure 4A, B, C).

\section{Discussion}

The present study evaluated the antioxidant effects of biofunctional feed generated through supplementation of the conventional feed with OMW when it was administered in lambs during the first 70 days of their lives. Specifically, the activities of two fundamental antioxidant enzymes, namely GST and SOD were determined and the expression of $\gamma$ GCL protein was also assessed in three tissues. We report that OMW exerted potent antioxidant action intensifying the redox profile of lamb tissues in a tissue-specific manner. Mechanistically, it appears that the path of GSH synthesis 
A

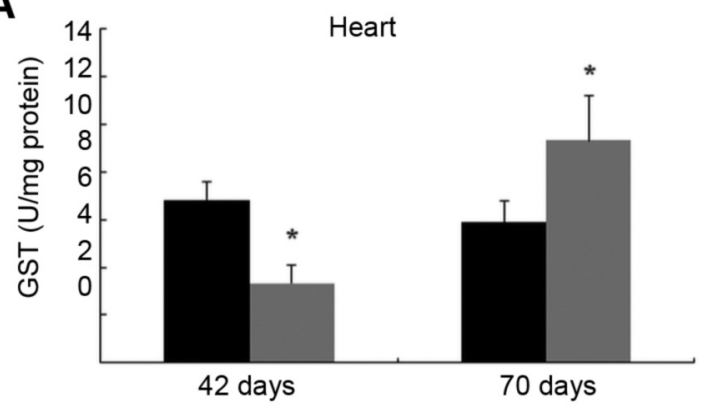

B

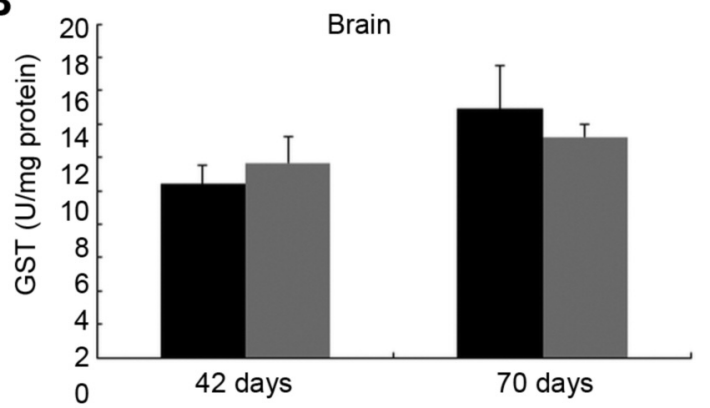

C

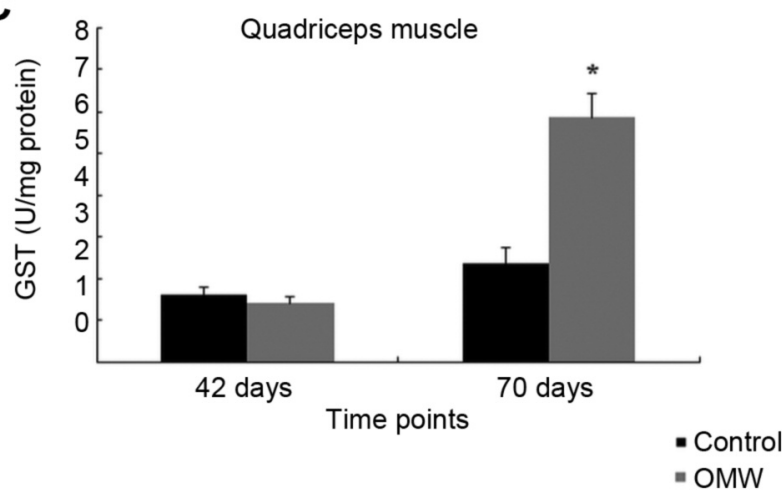

Figure 2. The effects of biofunctional feed supplemented with olive oil mill wastewater $(O M W)$ byproducts on the enzymatic activity of glutathione-S-transferase (GST) in the heart (A), brain (B) and quadriceps muscle $(C)$ on days 42 and $70 . *$ Statistically significant compared to the control at the same time point $(p<0.05)$.

partially contributes to the beneficial effects of OMW when it is incorporated in a biofunctional feed, as it can be deduced by our results in combination with the findings of a previous relevant study (3).

Diet is the cornerstone for animal welfare and productivity $(22,25)$. It is known that productive animals in young age suffer from several oxidative stress related diseases (e.g., mastitis, enteritis, pneumonia, sepsis) since they typically have reduced antioxidant arsenal compared to adults $(21,46)$. For instance, the weaning period in pigs constitutes a stressful situation that causes several pathologies, such as gastrointestinal disorders which are directly associated with
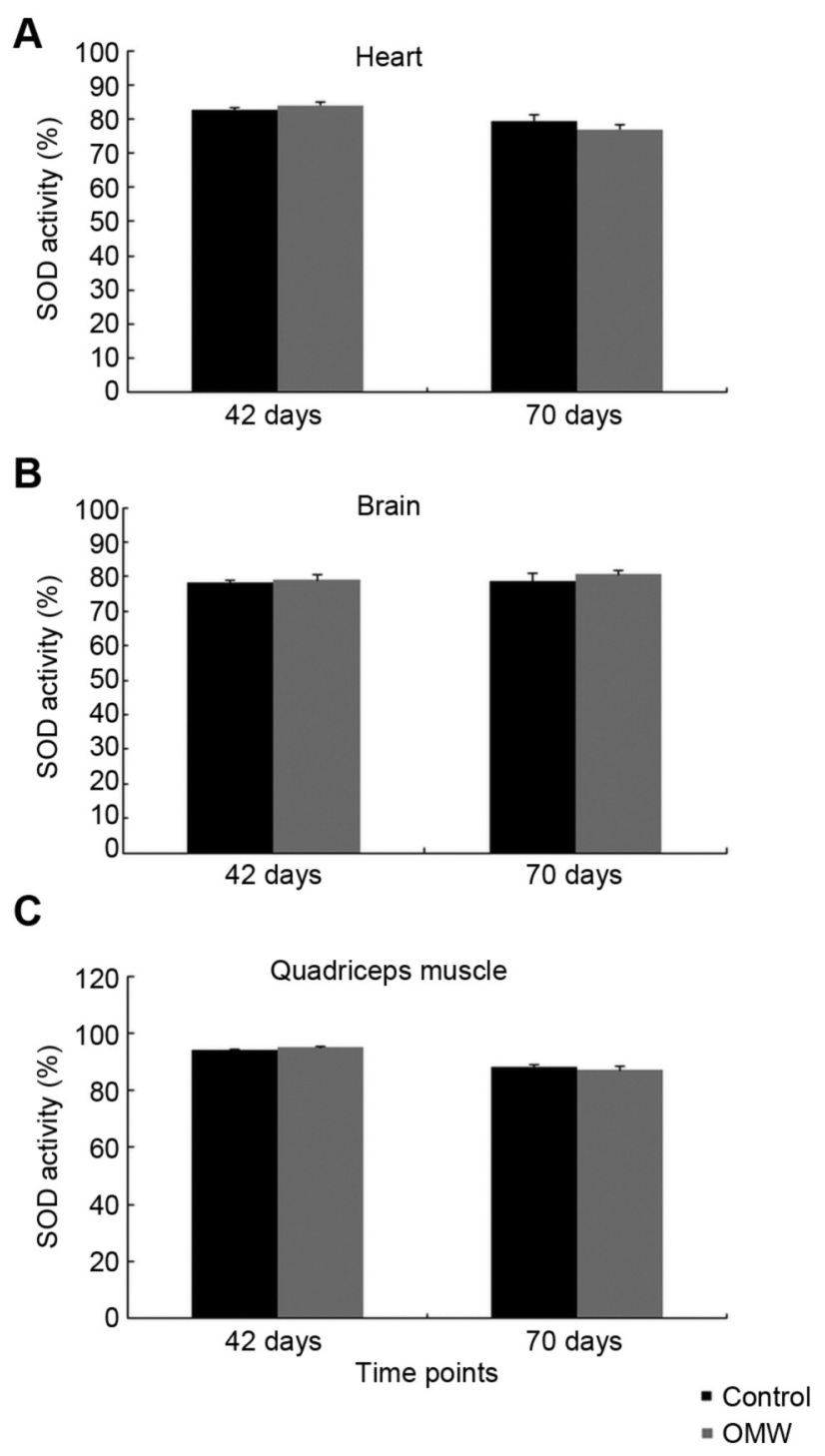

Figure 3. The effects of biofunctional feed supplemented with olive oil mill wastewater (OMW) byproducts on the enzymatic activity of superoxide dismutase (SOD) in the heart $(A)$, brain $(B)$ and quadriceps muscle $(C)$ on days 42 and 70.

impaired antioxidant mechanisms (47, 48). The aforementioned conditions contribute to the reduction of their welfare and productivity (22). In order to intensify their antioxidant defense system and to protect them from oxidative stress related diseases, supplementation with feed rich in polyphenolic additives appears to be an appropriate regimen. Polyphenols are considered the most important and abundant antioxidants present in fruits, vegetables and plant derivatives $(29,49,50)$. Thus, animal diets rich in polyphenols can protect them against a number of diseases associated with disrupted redox equilibrium and also enhance their productivity, a fact that is important regarding the economic impact on the 
A

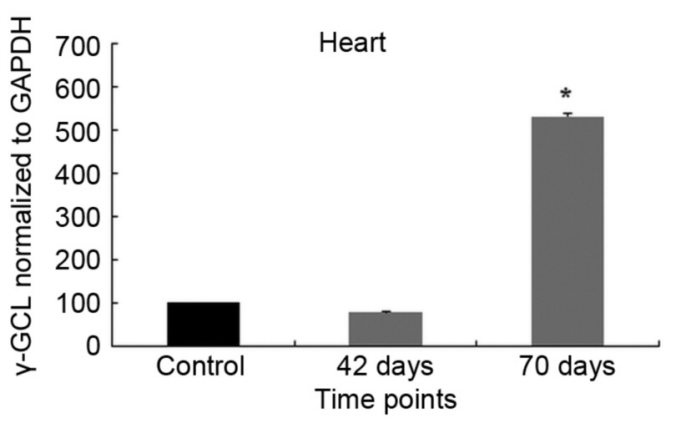

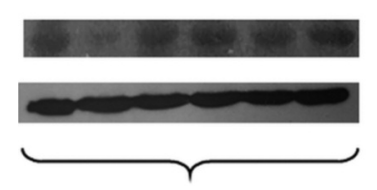

Control 42d

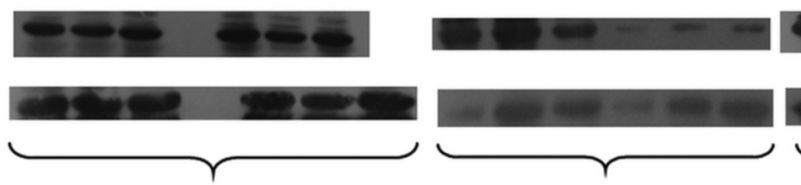

Control 70d

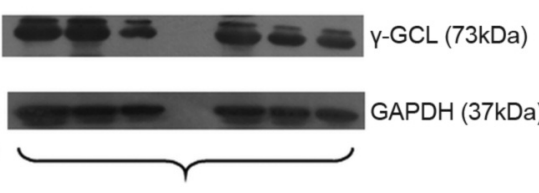

B
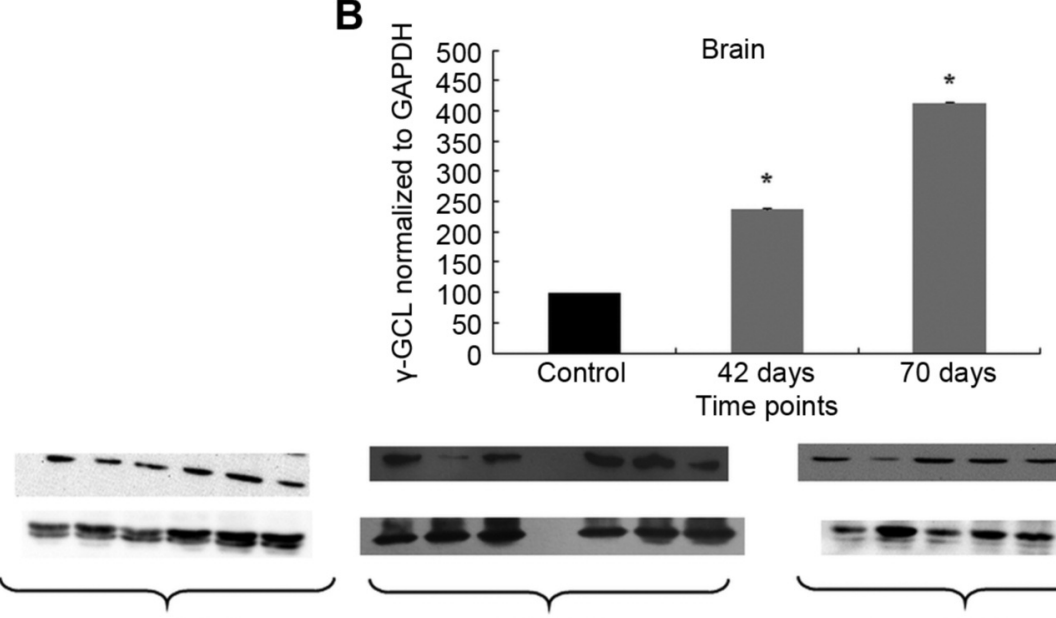

Control 42d
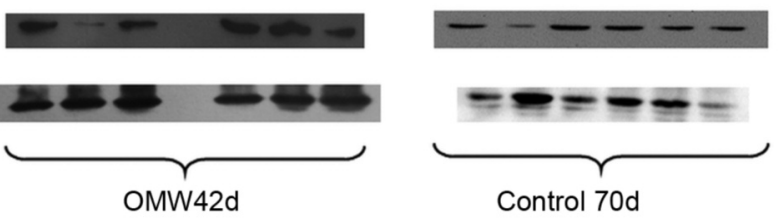

Control 70d

OMW70d

\section{C}

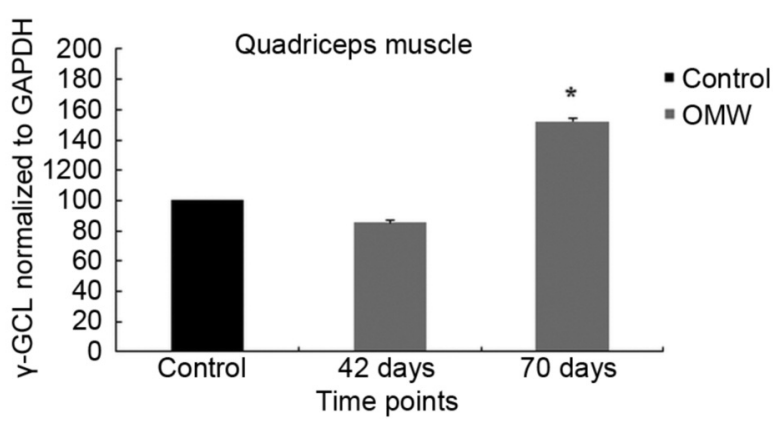

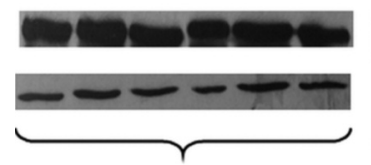

Control 42d

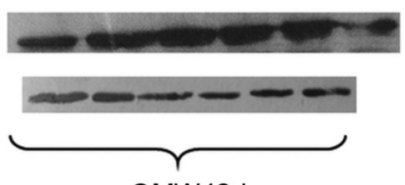

OMW42d

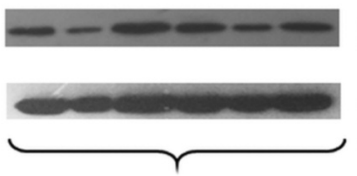

Control 70d

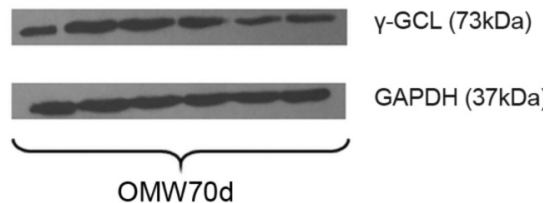

OMW70d

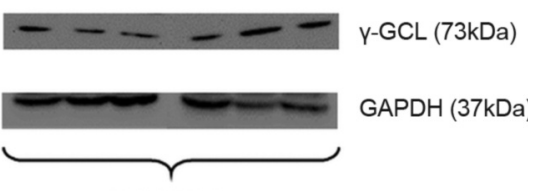

Figure 4. Western blot analysis showing the effects of feed supplemented with olive oil mill wastewater (OMW) byproducts on the protein expression of $\gamma$-glutamate-cysteine ligase $(\gamma-G C L)$ in the heart $(A)$, brain $(B)$ and quadriceps muscle $(C)$ on days 42 and 70 . All results are expressed as \% percentage of the control group. GAPDH expression was used as loading control for normalization. Densitometric quantification of all enzymes is also depicted. *Statistically significant compared to the control $(p<0.05)$. 
primary production section $(51,52)$. Previous studies from our research group have shown that feed supplemented with byproducts from wineries and olive oil industries reduce lipid and protein oxidation reinforcing animal health, since these oxidative modifications are capable of destroying the integrity of cell membranes, and thus lead to cell death (3, 31-33). Moreover, polyphenols that are contained in the aforementioned wastes may improve meat quality, since lipid oxidation is one of the main causes of meat taste deterioration and loss of nutritional value $(53,54)$.

It is worth mentioning that high concentrations of reactive species are also responsible for several pathologies of the heart $(55,56)$, whereas they are associated with brain aging (57), muscle diseases since skeletal muscle is susceptible to oxidative stress (58-60). Other studies have shown that protein and lipid oxidation reduces the taste and nutritional value of meat products, so it is crucial to estimate the redox status in this tissue, since muscle is included in human diet $(53,61,62)$. Molecules of the tissue antioxidant defense and especially GST, SOD and $\gamma$-GCL are three of the most substantial biomarkers of redox equilibrium. GSTs are major phase II enzymes found mainly in the cytosol, contributing to the metabolism and detoxification of a wide range of xenobiotics by catalyzing their conjugation with the thiol group of reduced glutathione (GSH) and to apoptosis (6365). SOD is an enzyme involved in the scavenging of superoxide radical, since it reduces it to hydrogen peroxide playing a crucial role in the antioxidant defense against oxidative stress $(66,67)$. Finally, $\gamma$-GCL is the first enzyme in the biosynthetic pathway of GSH. Glutathione synthesis consists of two enzymatic steps: (a) the $\gamma$-glutamylcysteine formation by L-glutamate, cysteine and glycine, a rate limiting step that is catalyzed by $\gamma$-GCL and (b) the GSH formation from $\gamma$-glutamylcysteine and glycine by glutathione synthase $(7,68)$.

It seems that OMW exerts beneficial effects in all studied tissues partially through GSH and its biosynthesis pathway. On day 42, GST in the OMW group was decreased in the heart and $\gamma$-GCL expression was increased in the brain, whereas no alterations were observed in any other tissue. However, on day 70 the levels of these two enzymes were significantly increased. Specifically, GST in the OMW group was increased in the heart and muscle and $\gamma$-GCL expression was increased in all tested tissues. According to previous findings from the same experiment, GSH levels were not affected on day 42 in the heart and muscle but they were increased in the brain, whilst they were significantly increased on day 70 in all studied tissues (3). Given that GST uses GSH in order to detoxify xenobiotic and electrophile compounds, the changes in GSH levels on day 42 are not in agreement with our findings in the three tested tissues. It appears that other enzymes, which participate in the GSH cycle, such as glutathione reductase (GR) and glutathione peroxidase (GPx) may have been activated. (3). The increased $\gamma$-GCL protein expression may lead to the de novo synthesis of GSH in order to balance the possible reduction due to the increased GST activity. Masella et al. have reported that olive oil polyphenols, such as oleuropein, increase GR and GPx activities in macrophages (68). Regarding the muscle, Kerasioti et al. (7) have shown that GR seems to be also activated. In addition, Martín et al. have mentioned that olive oil polyphenols, such as hydroxytyrosol, increase the enzymatic activity and expression of GSH-related enzymes, such as GR, GPx, GST via the Nrf2 signaling pathway (69). Kouka et al. have also demonstrated that Greek olive oils with different polyphenolic composition increase the expression of genes coding for antioxidant enzymes in different cell lines (70). The fact that the GST activity was not changed in the brain may be due to the activity of other antioxidant enzymes, such as catalase and GPx (7). The increased levels of $\gamma$-GCL expression can be justified by the increased GSH concentration. Indeed, our group has previously shown that feed supplemented with byproducts from wineries and olive oil industries affected the levels of these enzymes in many tissues, such as the liver and spleen, and enhanced animal antioxidant mechanisms through the increased levels of redox biomarkers (9, 31-33, 62, 71). Furthermore, Goutzourelas et. al. have demonstrated that polyphenols present in grape pomace, a byproduct of wine processing, increase gammaglutamylcysteine synthetase ( $\gamma$-GCS) levels and GST activity in muscle and endothelial cells (72). Apart from the enzymes comprising (among others) the GSH pathway (i.e., GST, $\gamma$ GCL), SOD was found to be unaffected in all tested tissues. This result is in line with a previous study of ours showing that SOD was not affected in muscle and endothelial cells after administration of grape pomace derived from wine byproducts rich in polyphenols (72).

The aforementioned beneficial effects of OMW are basically attributed to its polyphenolic compounds content. The biofunctional feed supplemented with OMW exerted two-fold higher antioxidant activity than the standard/conventional feed (3) and, additionally, many studies have already reported that polyphenols partially modulate the activity of phase I and phase II enzymes, particularly enzymes which are related to the GSH biosynthetic pathway (73-75). Moreover, polyphenols of OMW, such as hydroxytyrosol, may induce the GST gene and protein expression in cells via the Nrf2 pathway (69), which is an important defense mechanism against oxidative stress (76). Under normal conditions, Nrf2 is anchored with a protein named kelch-like ECH-associated protein 1 (Keap1) in the cytoplasm. This protein contains reactive cysteine molecules that can be modified be several oxidative stimuli and polyphenols (77). As a result, Nrf2 translocates to the nucleus and activates the antioxidant response elements (AREs) of antioxidant enzyme genes, such as $\gamma$ - 
GCL and GST (78-80). In addition, GST activity increases in aged animals probably as a compensatory mechanism against aging-promoting products $(81,82)$.

\section{Conclusion}

The present study showed that biofunctional feed supplemented with byproducts of olive oil industry (i.e., the olive mill wastewater, OMW) improved the antioxidant profile of vital tissues of lambs, such as the heart, brain and muscle. Specifically, OMW increased the enzymatic activity of GST, which is responsible for the detoxification of xenobiotics, while it also increased the protein expression of $\gamma$-GCL, a key enzyme in GSH biosynthesis in all the aforementioned tissues. The OMW exerted tissue specific action probably due to different tissue physiology and response to oxidative stress, as well as to the presence of different antioxidant molecules in each of them. It is noteworthy that the literature lacks reports on the exploitation of OMW. Therefore, this is a notable novelty of the present study indicating that the generation of biofunctional feed containing this polyphenol-rich byproduct is a putative alternative and cost-effective intervention in order to enhance animal productivity and promote their welfare by protecting them against oxidative stress related pathologies. Finally, OMW exploitation will result in environmental pollution reduction since it is a substance with high organic content that threatens the quality of the environment when discarded.

\section{Conflicts of Interest}

The Authors declared that they have no competing interests regarding this study.

\section{Authors' Contributions}

Methodology: Makri Sotiria, Kouretas Demetrios; Conceptualization: Kouretas Demetrios

Validation: Makri Sotiria, Kouretas Demetrios; Investigation: Makri Sotiria, Raftopoulou Sofia, Kafantaris Ioannis, Kotsampasi Basiliki, Christodoulou Vladimiros; Resources: Kouretas Demetrios, Kotsampasi Basiliki, Christodoulou Vladimiros; Writing-original draft preparation: Makri Sotiria; Writing-review and editing: Veskoukis Aristidis S., Kouretas Demetrios, Nepka Charitini; Visualization: Makri Sotiria; Supervision: Kouretas Demetrios; Project administration: Makri Sotiria, Kafantaris Ioannis, Kouretas Demetrios.

Funding acquisition: Kouretas Demetrios.

\section{Acknowledgements}

This research is co-financed by Greece and the European Union (European Social Fund- ESF) through the Operational Programme «Human Resources Development, Education and Lifelong Learning» in the context of the project "Scholarships programme for post-graduate studies - 2 $2^{\text {nd }}$ Study Cycle" (MIS-5003404), implemented by the State Scholarships Foundation (IKY).

\section{References}

1 International Olive Council., 2011. Available from: www.internationaloliveoil.org. (Last accessed 15/04/20)

2 IPPC Directive, Council Directive 96/61/EC of 24 September 1996 concerning integrated pollution prevention and control, 1996.

3 Makri S, Kafantaris I, Savva S, Ntanou P, Stagos D, Argyroulis I, Kotsampasi B, Christodoulou V, Gerasopoulos K, Petrotos K, Komiotis D and Kouretas D: Novel feed including olive oil mill wastewater bioactive compounds enhanced the redox status of lambs. In Vivo 32: 291-302, 2018. PMID: 29475912. DOI: 10.21873/invivo.11237

4 Michailides M, Panagopoulos P, Akratos CS, Tekerlekopoulou AG and Vayenas D V: A full-scale system for aerobic biological treatment of olive mill wastewater. J Chem Technol Biotechnol 86: 888-892, 2011. DOI: $10.1002 /$ jctb.2601

5 Karahan Ozgun O, Pala Ozkok I, Kutay C and Orhon D: Characteristics and biodegradability of olive mill wastewaters. Environ Technol 37: 1240-1248, 2016. PMID: 26507588. DOI: 10.1080/09593330.2015.1110204

6 Pelendridou K, Michailides MK, Zagklis DP, Tekerlekopoulou AG, Paraskeva CA and Vayenas DV: Treatment of olive mill wastewater using a coagulation-flocculation process either as a single step or as post-treatment after aerobic biological treatment. J Chem Technol Biotechnol 89: 1866-1874, 2014. DOI $10.1002 /$ jctb.4269

7 Kerasioti E, Terzopoulou Z, Komini O, Kafantaris I, Makri S, Stagos D, Gerasopoulos K, Anisimov NYNY, Tsatsakis AMAM and Kouretas D: Tissue specific effects of feeds supplemented with grape pomace or olive oil mill wastewater on detoxification enzymes in sheep. Toxicol Rep 4: 364-372, 2017. PMID: 28959661. DOI: 10.1016/j.toxrep.2017.06.007

8 Frankel E, Bakhouche A, Lozano-Sanchez J, Segura-Carretero A and Fernandez-Gutierrez A: Literature review on production process to obtain extra virgin olive oil enriched in bioactive compounds. Potential use of byproducts as alternative sources of polyphenols. J Agric Food Chem 61: 5179-5188, 2013. PMID: 23656613. DOI: 10.1021/jf400806z

9 Papadopoulou A, Petrotos K, Stagos D, Gerasopoulos K, Maimaris A, Makris H, Kafantaris I, Makri S, Kerasioti E, Halabalaki M, Brieudes V, Ntasi G, Kokkas S, Tzimas P, Goulas P, Zakharenko AMA, Golokhvast KKS, Tsatsakis A and Kouretas D: Enhancement of antioxidant mechanisms and reduction of oxidative stress in chickens after the administration of drinking water enriched with polyphenolic powder from olive mill waste waters. Oxid Med Cell Longev 2017: 1-10, 2017. PMID: 29138680. DOI: 10.1155/2017/8273160

10 Maalej A, Bouallagui Z, Hadrich F, Isoda H and Sayadi S: Assessment of Olea europaea L. fruit extracts: Phytochemical characterization and anticancer pathway investigation. Biomed Pharmacother 90: 179-186, 2017. PMID: 28360012. DOI: 10.1016/j.biopha.2017.03.034

11 Veskoukis A, Kerasioti E, Priftis A, Kouka P, Spanidis Y, Makri $S$ and Kouretas D: A battery of translational biomarkers for the assessment of the in vitro and in vivo antioxidant action of plant polyphenolic compounds: The biomarker issue. Curr Opin Toxicol 13: 99-109, 2019. DOI: 10.1016/j.cotox.2018.10.001 
12 Tresserra-Rimbau A, Arranz S and Vallverdu-Queralt A: New insights into the benefits of polyphenols in chronic diseases. Oxid Med Cell Longev 2017: 1432071, 2017. PMID: 29348785. DOI: $10.1155 / 2017 / 1432071$

13 Cicerale S, Lucas L and Keast R: Biological activities of phenolic compounds present in virgin olive oil. Int J Mol Sci 11: 458-479, 2010. PMID: 20386648. DOI: 10.3390/ijms 11020458

14 Gorinstein S, Leontowicz H, Lojek A, Leontowicz M, Ciz M, Krzeminski R, Gralak M, Czerwinski J, Jastrzebski Z, Trakhtenberg S, Grigelmo-Miguel N, Soliva-Fortuny R and Martin-Belloso O: Olive oils improve lipid metabolism and increase antioxidant potential in rats fed diets containing cholesterol. J Agric Food Chem 50: 6102-6108, 2002. PMID: 12358487. DOI: $10.1021 / \mathrm{jf0} 20306 \mathrm{k}$

15 Lobo V, Patil A, Phatak A and Chandra N: Free radicals, antioxidants and functional foods: Impact on human health. Pharmacogn Rev 4: 118-126, 2010. PMID: 22228951. DOI: 10.4103/0973-7847.70902

16 Rahman K: Studies on free radicals, antioxidants, and co-factors. Clin Interv Aging 2: 219-236, 2007. PMID: 18044138.

17 de Bock M, Thorstensen EB, Derraik JGB, Henderson H V, Hofman PL and Cutfield WS: Human absorption and metabolism of oleuropein and hydroxytyrosol ingested as olive (Olea europaea L.) leaf extract. Mol Nutr Food Res 57: 2079-2085, 2013. PMID: 23766098. DOI: $10.1002 / \mathrm{mnfr} .201200795$

18 Nabavi SF, Braidy N, Orhan IE, Badiee A, Daglia M and Nabavi SM: Rhodiola rosea L. and Alzheimer's disease: From farm to pharmacy. Phyther Res 30: 532-539, 2016. PMID: 27059687. DOI: $10.1002 /$ ptr.5569

19 Castejón ML, Montoya T, Alarcón-de-la-Lastra C and SánchezHidalgo M: Potential protective role exerted by secoiridoids from Olea europaea L. in cancer, cardiovascular, neurodegenerative, aging-related, and immunoinflammatory diseases. Antioxidants (Basel, Switzerland) 9: 149, 2020. PMID: 32050687. DOI: 10.3390/antiox 9020149

20 World Organisation for Animal Health. Anim Welf. Available from: http://www.oie.int/en/.

21 Lykkesfeldt $\mathbf{J}$ and Svendsen O: Oxidants and antioxidants in disease: oxidative stress in farm animals. Vet J 173: 502-511, 2007. PMID: 16914330. DOI: 10.1016/j.tvj1.2006.06.005

22 Skaperda Z, Veskoukis AS and Kouretas D: Farm animal welfare, productivity and meat quality: Interrelation with redox status regulation and antioxidant supplementation as a nutritional intervention (Review)le. World Acad Sci J 1: 177-183, 2019. DOI: $10.3892 /$ wasj.2019.19

23 Celi P and Gabai G: Oxidant/antioxidant balance in animal nutrition and health: The role of protein oxidation. Front Vet Sci 2: 48, 2015. PMID: 26664975. DOI: 10.3389/fvets.2015.00048

24 Chan JKW, Charrier JG, Kodani SD, Vogel CF, Kado SY, Anderson DS, Anastasio C and Van Winkle LS: Combustionderived flame generated ultrafine soot generates reactive oxygen species and activates Nrf2 antioxidants differently in neonatal and adult rat lungs. Part Fibre Toxicol 10: 34, 2013. PMID: 23902943. DOI: 10.1186/1743-8977-10-34

25 Veskoukis A, Kerasioti E, Sidiropoulos K, Maragou I and Kouretas D: Nutritional habits and free grazing regimen of productive animals along with specific ingredients are influential factors for the antioxidant properties of milk: From farm to market. Biomed Rep, 2020. (article in press)
26 Bouroutzika E, Kouretas D, Papadopoulos S, Veskoukis AS, Theodosiadou E, Makri S, Paliouras C, Michailidis ML, Caroprese $\mathrm{M}$ and Valasi I: Effects of melatonin administration to pregnant ewes under heat-stress conditions, in redox status and reproductive outcome. Antioxidants (Basel, Switzerland) 9, 2020. PMID: 32210209. DOI: 10.3390/antiox9030266

27 Kris-Etherton PM, Hecker KD, Bonanome A, Coval SM, Binkoski AE, Hilpert KF, Griel AE and Etherton TD: Bioactive compounds in foods: their role in the prevention of cardiovascular disease and cancer. Am J Med 113: 71S-88S, 2002. PMID: 12566142. DOI: 10.1016/s0002-9343(01)00995-0

28 Chaiyotwittayakun A, Erskine RJ, Bartlett PC, Herd TH, Sears PM and Harmont RJ: The effect of ascorbic acid and L-histidine therapy on acute mammary inflammation in dairy cattle. J Dairy Sci 85: 60-67, 2002. PMID: 11860122. DOI: 10.3168/jds.s00220302(02)74053-8

29 Pandey KB and Rizvi SI: Plant polyphenols as dietary antioxidants in human health and disease. Oxid Med Cell Longev 2: 270-278, 2009. PMID: 20716914. DOI: 10.4161/ oxim.2.5.9498

30 Paiva-Martins F, Fernandes J, Rocha S, Nascimento H, Vitorino R, Amado F, Borges F, Belo L and Santos-Silva A: Effects of olive oil polyphenols on erythrocyte oxidative damage. Mol Nutr Food Res 53: 609-616, 2009. PMID: 19340892. DOI: $10.1002 / \mathrm{mnfr} .200800276$

31 Makri S, Kafantaris I, Stagos D, Chamokeridou T, Petrotos K, Gerasopoulos K, Mpesios A, Goutzourelas N, Kokkas S, Goulas $\mathrm{P}$, Komiotis D and Kouretas D: Novel feed including bioactive compounds from winery wastes improved broilers' redox status in blood and tissues of vital organs. Food Chem Toxicol 102: 24-31, 2017. PMID: 28130089. DOI: 10.1016/j.fct.2017.01.019

32 Gerasopoulos K, Stagos D, Petrotos K, Kokkas S, Kantas D, Goulas P and Kouretas D: Feed supplemented with polyphenolic byproduct from olive mill wastewater processing improves the redox status in blood and tissues of piglets. Food Chem Toxicol 86: 319-327, 2015. PMID: 26561741. DOI: 10.1016/j.fct. 2015.11.007

33 Gerasopoulos K, Stagos D, Kokkas S, Petrotos K, Kantas D, Goulas P and Kouretas D: Feed supplemented with byproducts from olive oil mill wastewater processing increases antioxidant capacity in broiler chickens. Food Chem Toxicol 82: 42-49, 2015. PMID: 25916917. DOI: 10.1016/j.fct.2015.04.021

34 Kerasioti E, Stagos D, Tsatsakis AM, Spandidos DA, Taitzoglou I and Kouretas D: Effects of sheep/goat whey protein dietary supplementation on the redox status of rats. Mol Med Rep 17: 5774-5781, 2018. PMID: 29484396. DOI: $10.3892 / \mathrm{mmr}$ 2018.8622

35 Kerasioti E, Veskoukis A, Virgiliou C, Theodoridis G, Taitzoglou I and Kouretas D: The strong antioxidant sheep/goat whey protein protects against mTOR overactivation in rats: A mode of action mimicking fasting. Antioxidants (Basel, Switzerland) 8 , 2019. PMID: 30909557. DOI: 10.3390/antiox 8030071

36 Bari H and Ramaj P: The impact of waste from olive oil production in the environment, Conference: The international Conference of the project Adriatic AOGRPSL 245 "The Adriatic Olive Grove: Risk Prevention, Sustainability, Learning", 2014.

37 Pavlidou A, Anastasopoulou E, Dassenakis M, Hatzianestis I, Paraskevopoulou V, Simboura N, Rousselaki E and Drakopoulou P: Effects of olive oil wastes on river basins and an oligotrophic coastal marine ecosystem: a case study in Greece. Sci Total 
Environ 497-498: 38-49, 2014. PMID: 25112823. DOI: 10.1016/j.scitotenv.2014.07.088

38 Paraskeva P and Diamadopoulos E: Technologies for olive mill wastewater (OMW) treatment: a review. J Chem Technol Biotechnol 81: 1475-1485, 2006. DOI: 10.1002/jctb.1553

39 Dordio A and Carvalho AJP: Constructed wetlands with light expanded clay aggregates for agricultural wastewater treatment. Sci Total Environ 463-464: 454-461, 2013. PMID: 23831791. DOI: $10.1016 /$ j.scitotenv.2013.06.052

40 Zagklis DP, Arvaniti EC, Papadakis VG and Paraskeva CA: Sustainability analysis and benchmarking of olive mill wastewater treatment methods. J Chem Technol Biotechnol 88: 742-750, 2013. DOI: $10.1002 /$ jctb.4036

41 Kouka P, Tekos F, Valta K, Mavros P, Veskoukis AS, Angelis A, Skaltsounis A-L and Kouretas D: Omicronlive tree blossom polyphenolic extracts exert antioxidant and antimutagenic activities in vitro and in various cell lines. Oncol Rep 42: 28142825, 2019. PMID: 31661143. DOI: 10.3892/or.2019.7386

42 Kouka P, Tekos F, Papoutsaki Z, Stathopoulos P, Halabalaki M, Tsantarliotou M, Zervos I, Nepka C, Liesivuori J, Rakitskii VN, Tsatsakis A, Veskoukis AS and Kouretas D: Olive oil with high polyphenolic content induces both beneficial and harmful alterations on rat redox status depending on the tissue. Toxicol Rep 7: 421-432, 2020. PMID: 32140426. DOI: 10.1016/j.toxrep.2020.02.007

43 Habig WH, Pabst MJ and Jakoby WB: Glutathione Stransferases. The first enzymatic step in mercapturic acid formation. J Biol Chem 249: 7130-7139, 1974. PMID: 4436300.

44 Veskoukis AS, Kyparos A, Paschalis V and Nikolaidis MG: Spectrophotometric assays for measuring redox biomarkers in blood. Biomarkers Biochem Indic Expo response, susceptibility to Chem 21: 208-217, 2016. PMID: 26809994. DOI: 10.3109/1354750X.2015.1126648

45 Oberley LW and Spitz DR: Assay of superoxide dismutase activity in tumor tissue. Methods Enzymol 105: 457-464, 1984. DOI: 10.1016/s0076-6879(84)05064-3

46 Jain A and Flora SJS: Dose related effects of nicotine on oxidative injury in young, adult and old rats. J Environ Biol 33: 233-238, 2012. PMID: 23033686.

47 Boudry G, Peron V, Le Huerou-Luron I, Lalles JP and Seve B: Weaning induces both transient and long-lasting modifications of absorptive, secretory, and barrier properties of piglet intestine. J Nutr 134: 2256-2262, 2004. PMID: 15333713. DOI: $10.1093 / \mathrm{jn} / 134.9 .2256$

48 Zhao KL, Zhu LH, Chen XL, Xu JX, Zhao KL, Chen XL and Xu JX: Impact of weaning and an antioxidant blend on intestinal barrier function and antioxidant status in pigs. J Anim Sci 90: 2581-2589, 2012. PMID: 22896732. DOI: 10.2527/jas.2012-4444

49 Lima GPP, Vianello F, Corrêa CR, Campos RA da S and Borguini MG: Polyphenols in fruits and vegetables and its effect on human health. Food Nutr Sci 5: 1065-1082, 2014. DOI: 10.4236/fns.2014.511117

50 Veskoukis AS, Vassi E, Poulas K, Kokkinakis M, Asprodini E, Haroutounian S and Kouretas D: Grape stem extracts from three native greek vine varieties exhibit strong antioxidant and antimutagenic properties. Anticancer Res 40: 2025-2032, 2020. PMID: 32234893. DOI: 10.21873/anticanres.14159

51 Umeno A, Horie M, Murotomi K, Nakajima Y and Yoshida Y: Antioxidative and antidiabetic effects of natural polyphenols and isoflavones. Molecules 21: 708, 2016. PMID: 27248987. DOI: 10.3390/molecules21060708
52 Taamalli A, Arráez-Román D, Zarrouk M, Segura-Carretero A and Fernández-Gutiérrez A: The occurrence and bioactivity of polyphenols in tunisian olive products and by-products: A review. J Food Sci 77: R83-R92, 2012. PMID: 22352878. DOI: 10.1111/j.1750-3841.2011.02599.x

53 Nam KC and Ahn DU: Use of antioxidants to reduce lipid oxidation and off-odor volatiles of irradiated pork homogenates and patties. Meat Sci 63: 1-8, 2003. PMID: 22061977. DOI: 10.1016/s0309-1740(02)00043-8

54 Arshad MS, Anjum FM, Khan MI, Shahid M, Akhtar S and Sohaib M: Wheat germ oil enrichment in broiler feed with alpha-lipoic acid to enhance the antioxidant potential and lipid stability of meat. Lipids Health Dis 12: 164, 2013. PMID: 24499336. DOI: $10.1186 / 1476-511 X-12-164$

55 Kobayashi A, Watanabe H, Ozawa K, Hayashi H and Yamazaki $\mathrm{N}$ : Oxygen-derived free radicals related injury in the heart during ischemia and reperfusion. Jpn Circ J 53: 1122-1131, 1989. PMID: 2557459. DOI: $10.1253 /$ jcj.53.1122

56 Kaul N, Siveski-Iliskovic N, Hill M, Slezak J and Singal PK: Free radicals and the heart. J Pharmacol Toxicol Methods 30: 55-67, 1993. PMID: 8298182. DOI: 10.1016/10568719(93)90008-3

57 Poon HF, Calabrese V, Scapagnini G and Butterfield DA: Free radicals and brain aging. Clin Geriatr Med 20: 329-359, 2004 PMID: 15182885. DOI: 10.1016/j.cger.2004.02.005

58 Hsu DZ, Chu PY, Wu PT, Shen PC and Jou IM: Oxidative stress participates in quadriceps muscle dysfunction during the initiation of osteoarthritis in rats. Int J Clin Exp Pathol 8: 1249112499, 2015. PMID: 26722436.

59 Veskoukis AS, Nikolaidis MG, Kyparos A, Kokkinos D, Nepka C, Barbanis S and Kouretas D: Effects of xanthine oxidase inhibition on oxidative stress and swimming performance in rats. Appl Physiol Nutr Metab 33: 1140-1154, 2008. PMID: 19088772. DOI: $10.1139 / \mathrm{H} 08-102$

60 Veskoukis AS, Margaritelis N V, Kyparos A, Paschalis V and Nikolaidis MG: Spectrophotometric assays for measuring redox biomarkers in blood and tissues: the NADPH network. Redox Rep 23: 47-56, 2018. PMID: 29088980. DOI: 10.1080/ 13510002.2017 .1392695

61 Zhang W, Xiao S and Ahn DU: Protein oxidation: basic principles and implications for meat quality. Crit Rev Food Sci Nutr 53: 1191-1201, 2013. PMID: 24007423. DOI: 10.1080/ 10408398.2011 .577540

62 Kafantaris I, Stagos D, Kotsampasi B, Hatzis A, Kypriotakis A, Gerasopoulos K, Makri S, Goutzourelas N, Mitsagga C, Giavasis I, Petrotos K, Kokkas S, Goulas P, Christodoulou V and Kouretas D: Grape pomace improves performance, antioxidant status, fecal microbiota and meat quality of piglets. Animal 12: 1-10, 2017. PMID: 28712376. DOI: 10.1017/S1751731117001604

$63 \mathrm{Wu}$ B and Dong D: Human cytosolic glutathione transferases: structure, function, and drug discovery. Trends Pharmacol Sci 33: 656-668, 2012. PMID: 23121834. DOI: 10.1016/j.tips. 2012.09.007

64 Singhal SS, Singh SP, Singhal P, Horne D, Singhal J and Awasthi S: Antioxidant role of glutathione S-transferases: 4Hydroxynonenal, a key molecule in stress-mediated signaling. Toxicol Appl Pharmacol 289: 361-370, 2015. PMID: 26476300. DOI: $10.1016 /$ j.taap.2015.10.006

65 Sheehan D, Meade G, Foley VM and Dowd CA: Structure, function and evolution of glutathione transferases: implications 
for classification of non-mammalian members of an ancient enzyme superfamily. Biochem J 360: 1-16, 2001. PMID: 11695986. DOI: 10.1042/0264-6021:3600001

66 Fridovich I: Superoxide dismutases. Adv Enzymol Relat Areas Mol Biol 58: 61-97, 1986. PMID: 3521218. DOI: 10.1002/ 9780470123041.ch2

67 Carlioz A and Touati D: Isolation of superoxide dismutase mutants in Escherichia coli: is superoxide dismutase necessary for aerobic life? EMBO J 5: 623-630, 1986. PMID: 3011417.

68 Masella R, Di Benedetto R, Varì R, Filesi C and Giovannini C: Novel mechanisms of natural antioxidant compounds in biological systems: involvement of glutathione and glutathionerelated enzymes. J Nutr Biochem 16: 577-586, 2005. PMID: 16111877. DOI: 10.1016/j.jnutbio.2005.05.013

69 Martín MA, Ramos S, Granado-Serrano AB, Rodríguez-Ramiro I, Trujillo M, Bravo L and Goya L: Hydroxytyrosol induces antioxidant/detoxificant enzymes and Nrf2 translocation via extracellular regulated kinases and phosphatidylinositol-3kinase/protein kinase B pathways in HepG2 cells. Mol Nutr Food Res 54: 956-966, 2010. PMID: 20166143. DOI: 10.1002/ mnfr.200900159

70 Kouka P, Tsakiri G, Tzortzi D, Dimopoulou S, Georgia, Sarikaki, Stathopoulos P, Veskoukis AS, Halabalaki M and Skaltsounis, Alexios-Leandros DK: The polyphenolic composition of extracts derived from 2 different Greek extra virgin olive oils is correlated with their 3 antioxidant potency. Oxid Med Cell Longev 2019: 1870965, 2019. PMID: 31015888. DOI: $10.1155 / 2019 / 1870965$

71 Kafantaris I, Kotsampasi B, Christodoulou V, Kokka E, Kouka P, Terzopoulou Z, Gerasopoulos K, Stagos D, Mitsagga C, Giavasis I, Makri S, Petrotos K and Kouretas D: Grape pomace improves antioxidant capacity and faecal microflora of lambs. J Anim Physiol Anim Nutr (Berl) 101(5): e108-e121, 2016. PMID: 27753147. DOI: $10.1111 /$ jpn.12569

72 Goutzourelas N, Stagos D, Housmekeridou A, Karapouliou C, Kerasioti E, Aligiannis N, Skaltsounis AL, Spandidos DA, Tsatsakis AM and Kouretas D: Grape pomace extract exerts antioxidant effects through an increase in GCS levels and GST activity in muscle and endothelial cells. Int J Mol Med 36: 433441, 2015. PMID: 26082074. DOI: 10.3892/ijmm.2015.2246

73 Boone CW, Kelloff GJ, Steele VE, Sharma S, Zhu S, Mehta R, Sigman CC, Bagheri D and Balentine D: Comparative chemopreventive mechanisms of green tea, black tea and selected polyphenol extracts measured by in vitro bioassays. Carcinogenesis 21: 63-67, 2000. PMID: 10607735. DOI: 10.1093/ carcin/21.1.63
74 Upadhyay S and Dixit M: Role of polyphenols and other phytochemicals on molecular signaling. Oxid Med Cell Longev 2015: 504253, 2015. PMID: 26180591. DOI: 10.1155/2015/ 504253

75 Han X, Shen T and Lou H: Dietary Polyphenols and Their Biological Significance. Int J Mol Sci 8: 950-988, 2007. DOI: 10.3390/i8090950

76 Nakagami Y: Nrf2 is an attractive therapeutic target for retinal diseases. Oxid Med Cell Longev 2016: 7469326, 2016. PMID: 27818722. DOI: $10.1155 / 2016 / 7469326$

77 Bensasson RV, Zoete V, Dinkova-Kostova AT and Talalay P: Two-step mechanism of induction of the gene expression of a prototypic cancer-protective enzyme by diphenols. Chem Res Toxicol 21: 805-812, 2008. PMID: 18361512. DOI: $10.1021 / \mathrm{tx} 7002883$

78 Osburn WO and Kensler TW: Nrf2 signaling: an adaptive response pathway for protection against environmental toxic insults. Mutat Res 659: 31-39, 2008. PMID: 18164232. DOI: 10.1016/j.mrrev.2007.11.006

79 Giudice A and Montella M: Activation of the Nrf2-ARE signaling pathway: a promising strategy in cancer prevention. Bioessays 28: 169-181, 2006. PMID: 16435293. DOI: 10.1002/ bies.20359

80 Panieri E, Buha A, Telkoparan-Akillilar P, Cevik D, Kouretas D, Veskoukis A, Skaperda Z, Tsatsakis A, Wallace D, Suzen S and Saso L: Potential applications of NRF2 modulators in cancer therapy. Antioxidants (Basel, Switzerland) 9, 2020. PMID: 32106613. DOI: $10.3390 /$ antiox 9030193

81 Maurya PK and Rizvi SI: Age-dependent changes in glutathioneS-transferase: correlation with total plasma antioxidant potential and red cell intracellular glutathione. Indian J Clin Biochem 25: 398-400, 2010. PMID: 21966113. DOI: 10.1007/s12291-010$0047-5$

82 Vyskocilova E, Szotakova B, Skalova L, Bartikova H, Hlavacova J and Bousova I: Age-related changes in hepatic activity and expression of detoxification enzymes in male rats. Biomed Res Int 2013: 408573, 2013. PMID: 23971034. DOI: $10.1155 / 2013 / 408573$ 